\title{
УДК 629.463.027.23
}

\section{А. Г. РЕЙДЕМЕЙСТЕР ${ }^{1}$, А. А. ШИКУНОВ ${ }^{2 *}$}

\author{
${ }^{1}$ Каф. «Вагоны и вагонное хозяйство», Днепропетровский национальный университет железнодорожного \\ транспорта имени академика В. Лазаряна, ул. Лазаряна, 2, Днепропетровск, Украина, 49010, тел. +38 (056) 3731504 , \\ эл. почта reidemeister@mail.ru, ORCID 0000-0001-7490-7180 \\ ${ }^{2 *}$ Каф. «Вагоны и вагонное хозяйство», Днепропетровский национальный университет железнодорожного \\ транспорта имени академика В. Лазаряна, ул. Лазаряна, 2, Днепропетровск, Украина, 49010, тел. +38 (056) 3731504 , \\ эл. почта tri_s@ua.fm, ORCID 0000-0002-8256-2634
}

\section{СПОСОБЫ УВЕЛИЧЕНИЯ ПРОЧНОСТИ БОКОВЫХ РАМ ТРЕХЭЛЕМЕНТНЫХ ТЕЛЕЖЕК}

Цель. В работе предполагается найти способы усиления конструкции боковой рамы тележки в местах концентрации напряжений (соединение поясов, углы челюстных и буксовых проемов и т. п.), где, как показывает опыт эксплуатации, возможно зарождение усталостных трещин. Следует избежать заметного увеличения массы конструкции и не вызвать «перетекания» областей с большими напряжениями из одних участков конструкции в другие. Методика. Напряжения в боковой раме авторы определяют путем конечноэлементного моделирования. Сначала выявляют подлежащие усилению участки конструкции. На следующем этапе разрабатывают возможные способы усиления (увеличение толщины стенок, изменение радиусов сопряжения, введение дополнительных ребер жесткости и проч.). После этого по результатам моделирования оценивают эффективность каждого метода. Усиление отдельных участков боковой рамы не всегда приводит к увеличению ее прочности в целом (уменьшение напряжений в одном месте зачастую приводит к росту напряжений в другом). Дальнейшая процедура носит итерационный характер: в конструкцию рамы вносят удачные изменения, вновь выявляют ослабленные участки конструкции и т. д., до достижения приемлемого уровня прочности. Результаты. Направленный итерационный поиск позволяет найти комбинацию локальных усилений, существенно увеличивающих прочность конструкции. А именно: увеличены радиусы перехода от колонки к опорной поверхности и в отверстии между колонкой и наклонным поясом до 40 и 50 мм соответственно; добавлены ребра жесткости между верхней и нижней полочкой направляющей триангеля, а также на внутренней направляющей челюстного проема; уменьшена на треть площадь технологического отверстия в колонке. За счет предлагаемой комбинации усилений напряжения в конструкции удалось снизить на 41 \%. Научная новизна. Учеными показана эффективность итерационной процедуры поиска комбинаций локальных усилений конструкции боковой рамы, позволяющих существенно увеличить ее прочность без значительного увеличения массы. Практическая значимость. Полученные результаты позволяют существенно повысить прочность боковой рамы трехэлементной тележки без заметного изменения ее геометрических и массовых характеристик.

Ключевые слова: боковая рама; трехэлементная тележка; прочность; модернизация; усиление

\section{Введение}

Конструкция боковой рамы трехэлементной тележки для грузовых вагонов кардинально не меняется с 1951 г. после ввода в эксплуатацию тележки типа МТ-50, заменившей поясные тележки. С развитием научно-технической мысли менялись и совершенствовались отдельные ее элементы, но сама боковая рама представляет собой стальную отливку, объединенные верхний, нижний, наклонные пояса и колонки которой образуют в средней части проем для размещения комплекта центрального рессорного подвешивания, а по концам - буксовые про- емы. Так же на боковой раме отлиты кронштейны для крепления и опирания различных элементов тележки.

Отличаются между собой различные конструкции боковых рам тележек сечением элементов и местами перехода одних элементов в другие. Необходимость разработки новых моделей боковых рам зачастую связано с введением в конструкцию тележки новых элементов или повышением осевой нагрузки $[3,4,5,9,10,16]$. Направлены новые разработки на повышение прочности и надежности боковой рамы и часто сводятся к выбору сечения отдельных элементов и оптимальных конструкторских решений 
в местах перехода одних элементов в другие. На последние зачастую наложены ограничения, связанные с взаимодействием боковых рам и других элементов тележки.

После создания модели новой боковой рамы для нее выполняется прочностной и усталостный расчеты, при которых выявляются участки, не выдерживающие нагрузки, предусмотренные «Нормами...» [6, 12, 13, 11]. А конструктор сталкивается с необходимостью увеличения прочности отдельных участков боковой рамы без значительного увеличения ее массы и изменения ее конструкции $[1,7,11,14,16,15]$. Этот этап работы конструктора в значительной мере может быть облегчен, если усиление модели проводить на основе результатов прочностного анализа при участии в их разработке специалистов, проводящих оценку прочности конструкции. Так как современные методы оценки прочности сложных конструкций, а именно метод конечных элементов (МКЭ) позволяют визуально выделить очаги концентрации напряжений, оценить поля распределения их распределения в конструкции, что позволяет более эффективно разрабатывать ее местное усиление [14].

Для исследования использовалась боковая рама трехэлементной тележки (рис. 1), конструкционными особенностями которой являются [2]:

- опирание в буксовом проеме не только через горизонтальные, но и через наклонные поверхности производится на упругий элемент буксового адаптера;

- наличие во внутреннем и наружном углах буксового проема разгрузочной канавки;

- наличие технологических отверстий в нижней части колонок центрального рессорного проема;

- отсутствие на верхнем поясе кронштейна для крепления подвески тормозного башмака - его заменила полочка для триангеля на наклонном поясе;

- наличие кронштейна для диагональных связей в зоне технологического окна;

- билинейное рессорное подвешивание и девять двухрядных пружин в центральном рессорном комплекте;

- для тележки после снятия пружин необходимо опустить надрессорную балку до упора в нижний пояс.

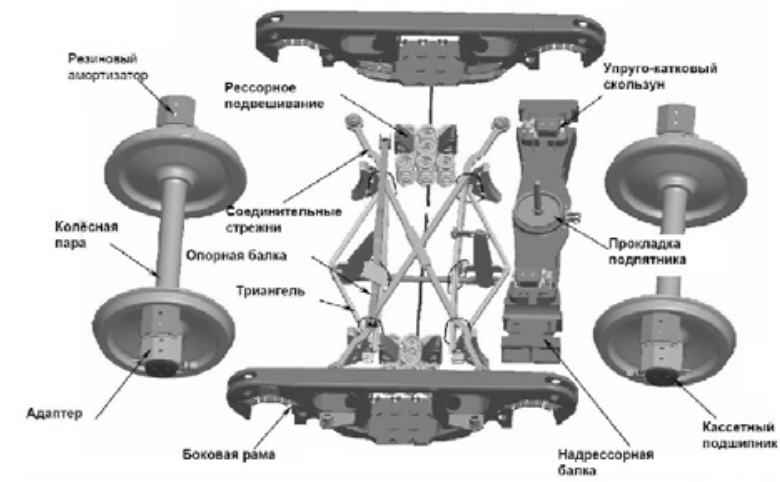

Рис. 1. Тележка нового поколения

Fig. 1. The bogie of new generation

\section{Цель}

Целью работы является поиск вариантов повышения прочности проблемных участков боковой рамы трехэлементной тележки без значительного увеличения ее массы и снижения прочности.

\section{Методика}

Оценка прочности данной боковой рамы проводилась согласно «Норм...». При этом были выявлены следующие участки, где возникающие в конструкции напряжения превышают допустимые значения (табл. 1). Допускаемые напряжения приведены для сталей, применяемых для изготовления тележек грузовых вагонов согласно ОСТ 32.183-2001 «Тележки двухосные грузовых вагонов колеи 1520 мм. Детали литые. Рама боковая и балка надрессорная. Технические условия» [8]. Минимальный предел текучести стали согласно ОСТ 32.183-2001 $\left[\sigma_{\mathrm{T}}\right]=294 \mathrm{MПа}$. Предельные допускаемые напряжения для данной стали приняты согласно [6] (см. табл. 1)

Конструкция не обеспечивает достаточную прочность во всех приведенных сечениях кроме наружного угла буксового проема и требует модернизации.

Участки боковой рамы, где напряжения превышают предельные допустимые значения, показаны на рис. 2, а нумерация участков соответствует табл. 1. 
Напряжения в элементах боковой рамы тележки

Table 1

Stresses in the elements of a side frame of a bogie

\begin{tabular}{|c|c|c|c|c|c|c|}
\hline \multirow[b]{2}{*}{ Зона боковой рамы } & \multicolumn{3}{|c|}{$\begin{array}{c}\text { I расчетный режим } \\
{[\sigma]=244 \mathrm{MПа}}\end{array}$} & \multicolumn{3}{|c|}{$\begin{array}{l}\text { III расчетный режим } \\
{[\sigma]=140 \mathrm{MПа}}\end{array}$} \\
\hline & 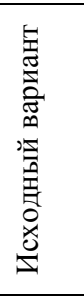 & 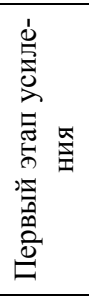 & 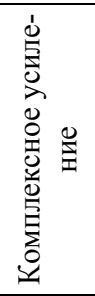 & 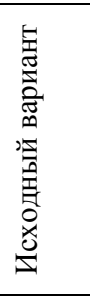 & 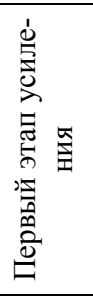 & 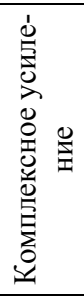 \\
\hline $\begin{array}{l}\text { Нижний угол центрального рессорного проема } \\
\text { с внутренней стороны (рис. 2) }\end{array}$ & 491 & 171 & 158 & 447 & 128 & 125 \\
\hline $\begin{array}{l}\text { Нижний угол центрального рессорного проема } \\
\text { с наружной стороны }\end{array}$ & 229 & 169 & 169,6 & 208 & 126 & 122 \\
\hline $\begin{array}{l}\text { Зона перехода от опорной поверхности централь- } \\
\text { ного рессорного проема к нижнему поясу }\end{array}$ & 264 & 236 & 219 & 185 & 128 & 128 \\
\hline Внутренний угол буксового проема & 219 & 225 & 149 & 187 & 194 & 128 \\
\hline Наружный угол буксового проема & 32 & 36 & 47 & 19 & 29 & 37 \\
\hline Нижний пояс & 198 & 168 & 152 & 176 & 144 & 133 \\
\hline $\begin{array}{l}\text { Технологическое окно возле кронштейна } \\
\text { для диагональных связей }\end{array}$ & 173 & 136 & 155 & 167 & 172 & 135 \\
\hline $\begin{array}{l}\text { Ребро перехода от верхней полочки триангеля } \\
\text { к нижней }\end{array}$ & - & 236 & 240 & - & 182 & 140 \\
\hline
\end{tabular}

Для усиления углов центрального рессорного проема рассмотрены следующие модернизации:

Ц1) ликвидация технологического отверстия в нижней части колонок. Данная модернизация не возможна в полном объеме, так как затрудняет формирование опок для отливок - уменьшена площадь отверстия и по периметру отверстие усилено буртом;

Ц2) увеличение радиуса угла центрального рессорного проема. Изменение возможно только на высоте буртов, ограничивающих опорную поверхность рессорного проема;

Ц3) увеличение длины вертикального ребра в нижнем поясе;

Ц4) установка ребер жесткости между колонками и опорной поверхностью рессорного проема с внутренней стороны боковой рамы рессорного комплекта. Высота ребер жесткости недолжна превышать высоту буртов, ограничивающих опорную поверхность рессорного проема, в противном случае усиление невозможно так как препятствует разборке тележки. Для усиления верхняя и нижняя полочки триангеля соединены вертикальным ребром, переходящим в бурты, ограничивающие опорную поверхность рессорного проема.

Для усиления внутреннего угла буксового проема рассмотрены три варианта:

Б1) увеличение толщины вертикальных поверхностей в зоне сопряжения верхнего и наклонного поясов;

Б2) увеличение толщины горизонтальной поверхности в зоне внутреннего угла буксового проема; 
Б3) ликвидация разгрузочной канавки в углу;

Б4) установка усиливающего ребра в проблемной зоне путем продления опорной поверхности для буксового адаптера.
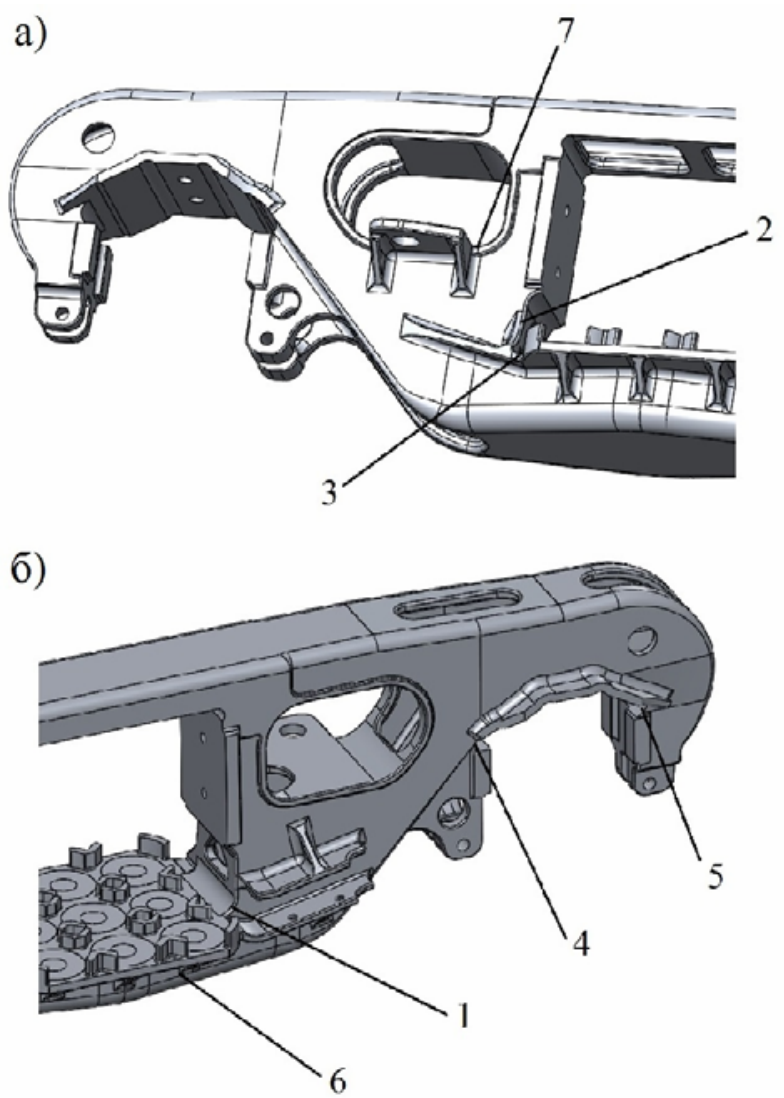

Рис. 2. Участки боковой рамы тележки, требующие усиления конструкции: $a-$ внешняя сторона рамы;
$\sigma-$ внутренняя сторона рамы.

Fig. 2. Sections of the side frame of a bogie, requiring structural reinforcements: $a$ - the outer side of the side frame; $b$ - the inner side of the side frame.

Для усиления технологического окна рассмотрены три варианта:

Т1) увеличение радиуса нижнего внутреннего угла технологического окна и толщины перемычки полоски для установки диагональных связей;

Т2) увеличение ширины усиливающего бурта вокруг технологического окна;

Т3) увеличение радиуса перехода от кронштейна диагональных связей к вертикальной плоскости боковой рамы.
Первый этап усиления конструкции наиболее благоприятно сказался на общем распределении напряжений по конструкции (табл. 1) и является основой для дальнейшей ее модернизации.

На первом этапе усиления произведено увеличение радиуса перехода от опорной поверхности центрального рессорного проема к колонке с 34 мм до 40 мм. Верхняя и нижняя полочки триангеля соединены вертикальным ребром, переходящим в бурты, ограничивающие опорную поверхность рессорного проема. А зона скругления нижнего угла рессорного проема продлена на усиливающие ребра.

Это позволило значительно снизить напряжения в нижнем углу центрального рессорного проема как с внутренней, так и с наружной стороны. Снизило уровень напряжений в зоне перехода от опорной поверхности центрального рессорного проема к нижнему поясу и в нижнем поясе в целом. Однако привело также к возрастанию напряжений во внутреннем углу буксового проема и технологическом окне на 5-8 МПа.

Также усиление привело к появлению новой зоны - ребро перехода от верхней полочки триангеля к нижней. Напряжения в данной зоне составили 236 и 187 МПа по I расчетному режиму (далее - p.p.). и III p.p. соответственно. Комбинации усилений моделей приведены в табл. 2.

Следующим шагом модернизации являлась ликвидация технологического отверстия в колонке. Это позволяло также снизить общий уровень напряжений в нижней зоне рессорного проема. Однако данный вид модернизации был отвергнут, так как наличие отверстия является обязательным для формирования литейной опоки, и его ликвидация приведет к значительным изменениям во внутреннем пространстве боковой рамы. В качестве альтернативы площадь данного отверстия была уменьшена, а кромка усилена буртом с внутренней стороны. Данная модернизация привела к перераспределению напряжений в нижней зоне рессорного комплекта и буксового узла, в целом положительному - напряжения повысились выше предельных допустимых значений только в зоне перехода от опорной поверхности центрального рессорного проема к нижнему поясу. 
А также вызвала рост напряжений в технологическом окне.

Таблица 2

Варианты комбинации усиления модели

Table 2

Possible combinations of the model reinforcement

\begin{tabular}{|c|c|}
\hline $\begin{array}{c}\text { Варианты модерни- } \\
\text { зации }\end{array}$ & Способы усиления конструкции \\
\hline $\begin{array}{c}\text { Первоначальный } \\
\text { вариант }\end{array}$ & $\begin{array}{c}\text { Ц2 (увеличен радиус } \\
\text { нижнего угла центрального } \\
\text { рессорного проема } \\
\text { с } 34 \text { мм до } 40 \text { мм); } \\
\text { Ц4 (толщина ребра, } \\
\text { связывающего верхнюю } \\
\text { и нижнюю полочки } \\
\text { триангеля } 15 \text { мм). }\end{array}$ \\
\hline $\begin{array}{c}\text { Комплексная } \\
\text { модернизация }\end{array}$ & $\begin{array}{c}\text { Ц2 (радиус увеличен } \\
\text { с } 34 \text { мм до } 40 \text { мм); } \\
\text { Ц4 (толщина ребра, } \\
\text { связывающего верхнюю } \\
\text { и нижнюю полочки } \\
\text { триангеля } 10 \text { мм); } \\
\text { Ц1 (площадь отверстия } \\
\text { уменьшена на } 35 \text { \%); } \\
\text { Б4 (длина ребра } 115 \text { мм); } \\
\text { Т1 (увеличен радиуса } \\
\text { нижнего внутреннего угла } \\
\text { технологического окна } \\
\text { с внутренней стороны } \\
\text { боковой рамы } \\
\text { с } 50 \text { до } 60 \text { мм); } \\
\text { Т3 (радиус увеличен } \\
\text { с } 10 \text { до } 50 \text { мм) }\end{array}$ \\
\hline
\end{tabular}

Также с целью снижения напряжений в нижней зоне рессорного комплекта было проведено увеличение длины продольного ребра жесткости, расположенного внутри нижнего пояса. Это привело к незначительному снижению напряжений в зоне нижнего угла центрального рессорного проема, однако вызвало значительное превышение допускаемых напряжений в зоне перехода вертикальной кромки ребра жесткости в верхний лист нижнего пояса.

На следующем этапе усиления конструкции внимание было сосредоточено на внутреннем углу буксового проема.
Для его усиления были опробованы варианты увеличения толщины вертикальных листов боковой рамы в зоне данного угла с 15 мм до 20 мм и увеличение толщины нижнего листа с 28 мм до 33 мм. Оба варианта не привели к значительным снижениям напряжений в зоне их концентрации. Также не дало результатов продольное ребро усиления, расположенное внутри боковой в зоне соединения верхнего и наклонного поясов рамы с внутренней стороны, высотой 15 мм и шириной 20 мм. Попытка ликвидации разгрузочной канавки во внутреннем углу буксового проема дало увеличение концентрации напряжений в проблемной зоне на 3-4 МПа.

Уменьшить напряжения в данной зоне ниже предельных допускаемых значений стало возможным в результате продления ребра опорной поверхности буксового проема вдоль наклонного пояса за зону внутреннего угла. Максимальные напряжения во внутреннем углу буксового проема снизились с 225 до 149 МПа и с 194 до 128 МПа при I р.p. и III p.p. соответственно.

При усилении технологического окна изменение радиуса его нижнего внутреннего угла и толщины перемычки полочки для установки диагональных связей привело к снижению напряжений до уровня 160 МПа при III p.p. Увеличение толщины усиливающего бурта с 16 до 18 мм по всему периметру привело к появлению очага высоких напряжений в верхнем наружном углу.

Снижению напряжений поспособствовало увеличение угла перехода от внешней части полочки для установки диагональных связей к вертикальной поверхности боковой рамы. В сочетании с увеличением радиуса нижнего внутреннего угла технологического окна это дало снижение напряжений со 172 до 132 МПа при III p.p.

После применения выше описанных модернизаций зона с напряжениями, превышающими предельные допускаемые значения, сохранилась только на ребре, соединяющем верхнюю и нижнюю полочки триангеля - 182 МПа при III p.p. Для ее устранения проводилось изменение радиусов перехода сопрягаемых элементов, а также их толщин. 
Изменение толщины данного ребра с 15 до 11 мм привело к снижению напряжений со 182 до 140 МПа, а дальнейшее уменьшение толщины до 9 мм вызвало возрастание напряжений до 151 МПа. Также результатов не дали разгрузочная канавка и ребро усиления в месте концентрации напряжений. Они вызвали при III p.p. скачек возникающих в зоне напряжений до 190 МПа и 205 МПа соответственно.

Так как эффект от уменьшения площади технологического отверстия в нижней части колонки незначителен, после комплексной модернизации выполнена оценка напряженного состояния при исходной площади отверстия. Возникающие в конструкции напряжения увеличились на 2-3 МПа.

\section{Результаты}

Полученная в результате комплексной модернизации боковая рама тележки отвечает требованиям нормативной документации (см. табл. 1), а уровень максимальных напряжений, возникающих в элементах конструкции, снижен на некоторых участках более чем в два раза.

\section{Научная новизна и практическая значимость}

Оценена целесообразность нескольких вариантов изменения конструкции боковой рамы трехэлементной тележки, направленных на местное усиление конструкции. А также их влияние на распределение напряжений в конструкции в целом.

Полученные результаты позволяют существенно повысить прочность боковой рамы трехэлементной тележки без заметного изменения ее геометрических и массовых характеристик.

\section{Выводы}

Выполненный анализ усилений боковой рамы тележки показал, что применение очевидных методов повышения прочности конструкции не всегда приводит к ожидаемым результатам, а само усиление сложно нагруженных конструкций при условии минимального изменения их массы должно выполнятся как комплекс взаимосвязанных модернизаций.

\section{СПИСОК ИСПОЛЬЗОВАННЫХ ИСТОЧНИКОВ}

1. Бороненко, Ю. П. Обобщение накопленного опыта проектирования тележек грузовых вагонов для создания их типоразмерного ряда / Ю. П. Бороненко, А. М. Орлова // Вісн. Дніпропетр. нац. ун-ту залізн. трансп. ім. акад. В. Лазаряна. - Дніпропетровськ, 2004. - Вип. 5. - C. 25-29.

2. Бубнов, В. М. Совершенствование конструкции боковой рамы двухосной тележки грузовых вагонов / В. М. Бубнов, Н. Б. Манкевич, С. В. Мямлин // Вагонный парк. - 2011. - № 2. - С. 36-39.

3. Давыдов, А. Н. Влияние продольных горизонтальных зазоров в боковых опорах непрерывного контакта на величину критической скорости грузового вагона / А. Н. Давыдов, А. В. Смольянинов // Вестн. Урал. гос. ун-та путей сообщения. - 2013. - № 1 (17). - С. 43-49.

4. Динамические качества грузовых вагонов, имеющих тележки с диагональными связями / Е. П. Блохин, К. Т. Алпысбаев, Р. Б. Грановский [и др.] // Вісн. Східноукр. нац. ун-ту ім. В. Даля. - Луганськ, 2012. - Вип. 5, ч. 1. C. $12-16$.

5. Мямлін, С. В. Прогнозування розвитку конструкції двовісного візка вантажного вагона / С. В. Мямлін, А. С. Мацюк // Вісн. Дніпропетр. нац. ун-ту залізн. трансп. ім. акад. В. Лазаряна. - Дніпропетровськ, 2009. - Вип. 27. - С. 24-29.

6. Нормы для расчета и проектирования вагонов железных дорог МПС колеи 1520 мм (несамоходных) (с изм. и доп. № 1 (с 01.02 .2000 г.) и № 2 (с 01.03.2002 г.). - Москва : ГосНИИВ : ВНИИЖТ, 1996. - 352 с.

7. Особенности рамы тележки грузового вагона и усталостная выносливость / А. Л. Голубенко, Л. А. Губачева, А. А. Андреев, С. Д. Мокроусов // Вісн. Східноукр. нац. ун-ту ім. В. Даля. - Луганськ, 2013. - Вип. 9 (1). - С. 7-16.

8. ОСТ 32.183-2001. Тележки двухосные грузовых вагонов колеи 1520 мм. Детали литые. Рама боковая и балка надрессорная. Технические условия. - Введ. 2002-05-01. - Москва : МПС России, 2001. - 22 с.

9. Пути совершенствования конструкции тележки грузового вагона / А. А. Босов, С. В. Мямлин, В. Я. Панасенко, И. В. Клименко // Вісн. Дніпропетр. нац. ун-ту залізн. трансп. ім. акад. В. Лазаряна. - Дніпропетровськ, 2009. - Вип. 29. - С. 27-32.

10. Харыбин, И. А. Совершенствовать ходовую часть грузовых вагонов / И. А. Харыбин, А. М. Орлова, 
А. В. Додонов // Вагоны и вагонное хоз-во. - 2009. - № 2 (18). - C. 26-29.

11. Bendsøe, M. P. Topology optimization. Theory, methods and applications / M. P. Bendsøe, O. Sigmund. - Berlin : Springer, 2004. - 370 p. doi: 10.1007/978-3-662-05086-6.

12. Bubnov, V. Theoretical And Experimental Investigations Of Strength Properties Of Cast Parts For Freight Cars Bogie With Axle Load Of $245 \mathrm{kN} /$ V. Bubnov, S. Myamlin, N. Mankevych // TRANSBALTICA 2013 : Selected Paper of the $8^{\text {th }}$ Intern. Conf. (09.05-10.05.2013) / Vilnius Gediminas Technical University. - Vilnius, 2013. P. 9-13. doi: 10.3846/transbaltica2013.003 .

13. Claus, H. Modeling and simulation of railway bogie structural vibrations / H. Claus, W. Schiehlen // Vehicle System Dynamics. - 1998. - Vol.
29. - Supp. 1. - P. 538-552. doi: 10.1080/00423119808969585.

14. Dietz, S. Fatigue life prediction of railway bogie under dynamic loads through simulation / S. Dietz, H. Netter, D. Sachau // Vehicle System Dynamics. - 1998. - Vol. 29. - Iss. 6. - P. 385402. doi: 10.1080/00423119808969381.

15. Optimum design of titling bogie frame in consideration of fatigue strength and weight / B. Park, N. Kim, Ju. Kim, K. Lee // Vehicle System Dynamics. - 2006. - Vol. 44. - Iss. 12. - P. 887-901. doi: $10.1080 / 00423110600737106$.

16. Park, B. U. Bogie frame design in consideration of fatigue strength and weight reduction / B. U. Park, K. Y. Lee // Proc. of the Institution of Mechanical Engineers. Part F. J. of Rail and Rapid Transit. 2006. - Vol. 220. - Iss. 3. - P. 201-206. doi: $10.1243 / 09544097 \mathrm{f} 01405$.

\title{
О. Г. РЕЙДЕМЕЙСТЕР ${ }^{1}$, О. А. ШИКУНОВ ${ }^{2 *}$
}

\begin{abstract}
${ }^{1}$ Каф. «Вагони та вагонне господарство», Дніпропетровській національний університет залізничного транспорту імені академіка В. Лазаряна, вул. Лазаряна, 2, Дніпропетровськ, Україна, 49010, тел. +38 (056) 3731504 , ел. пошта reidemeister@mail.ru, ORCID 0000-0001-7490-7180

$2^{2 *}$ Каф. «Вагони та вагонне господарство», Дніпропетровській національний університет залізничного транспорту імені академіка В. Лазаряна, вул. Лазаряна, 2, Дніпропетровськ, Україна, 49010, тел. +38 (056) 3731504 , ел. пошта tri_s@ua.fm, ORCID 0000-0002-8256-2634
\end{abstract}

\section{СПОСОБИ ЗБІЛЬШЕННЯ МІЦНОСТІ БІЧНИХ РАМ ТРЬОХЕЛЕМЕНТНИХ ВІЗКІВ}

Мета. В роботі передбачається знайти способи посилення конструкції бічної рами візка в місцях концентрації напружень (з'єднання поясів, кути щелепних та буксових прорізів і т. п.), де, як показує досвід експлуатації, можливе зародження втомних тріщин. Слід уникнути помітного збільшення маси конструкції та не викликати «перетікання» областей із великими напруженнями 3 одних ділянок конструкції в інші. Методика. Напруження в бічній рамі автори визначають шляхом скінченно-елементного моделювання. Спочатку виявляють ділянки конструкції, які підлягають посиленню. На наступному етапі розробляють можливі способи посилення (збільшення товщини стінок, зміна радіусів сполучення, введення додаткових ребер жорсткості та ін.). Після чого за результатами моделювання оцінюють ефективність кожного методу. Посилення окремих ділянок бічної рами не завжди призводить до збільшення ії міцності в цілому (зменшення напружень в одному місці часто призводить до зростання напружень в іншому). Подальша процедура носить ітераційний характер: в конструкцію рами вносять вдалі зміни, знову виявляють ослаблені ділянки конструкції і т. П., до досягнення прийнятного рівня міцності. Результати. Спрямований ітераційний пошук дозволяє знайти комбінацію локальних підсилень, що істотно збільшують міцність конструкції. Ними є: збільшені радіуси переходу від колонки до опорної поверхні та в отворі між колонкою і похилим поясом до 40 і 50 мм відповідно; додані ребра жорсткості між верхньою і нижньою поличкою направляючої триангеля, а також на внутрішній направляючій щелепного отвору, зменшена на третину площа технологічного отвору в колонці. За рахунок пропонованої комбінації підсилень напруження в конструкції вдалося знизити на 41 \%. Наукова новизна. Вченими показана ефективність ітераційної процедури пошуку комбінацій локальних підсилень конструкції бічної рами, що дозволяють істотно збільшити їі міцність без значного збільшення маси. Практична значимість. Отримані результати дозволяють істотно підвищити міцність бічної рами трьохелементного візка без помітної зміни ії геометричних та масових характеристик.

Ключові слова: бічна рама; трьохелементний візок; міцність; модернізація; посилення 


\title{
O. H. REIDEMEISTER ${ }^{1}$, O. A. SHYKUNOV ${ }^{*}$
}

\author{
${ }^{1}$ Dep. «Cars and Cars Facilities», Dnipropetrovsk National University of Railway Transport named after Academician \\ V. Lazaryan, Lazaryan St., 2, Dnipropetrovsk, Ukraine, 49010, tel. +38 (056) 373 15 04, e-mail reidemeister@mail.ru, \\ ORCID 0000-0001-7490-7180 \\ $2^{2 *}$ Dep. «Cars and Cars Facilities», Dnipropetrovsk National University of Railway Transport named after Academician \\ V. Lazaryan, Lazaryan St., 2, Dnipropetrovsk, Ukraine, 49010, tel. +38 (056) 373 15 04, e-mail tri_s@ua.fm, \\ ORCID 0000-0002-8256-2634
}

\section{STRENGTH INCREASE METHODS OF THE SIDE FRAME OF THE BOGIE IN THREE-PIECE TRUCKS}

Purpose. In the paper it is proposed to find methods of structural reinforcement of a side frame of a bogie in areas of stress concentration (the compound zone, the corners of the pedestal jaw opening, etc.), where, as the experience of operation shows, it is possible the emergence of fatigue cracks. It should avoid a significant increase in weight of the structure and does not cause «overflow» areas with a lot of stress from one portion of the structure to another. Methodology. The stresses in the side frame are determined by finite element modeling. Firstly parts of structure that is subject to be strengthened are detected. At the next stage the possible ways of enhancement are developed (wall thickness increase, change of fillet radii, introduction of additional truss plate, etc.). After which according to the results of simulation the effectiveness of each method is evaluated. Amplification of individual sections of the side frame does not always lead to its hardening as a whole (stress decrease in one place often leads to stress increase in the other one). The further procedure is iterative in nature: best-case changes are entered in the design of the frame; weakened areas of construction again are revealed and so on, till to the achievement an acceptable level of safety. Findings. Directional iterative search allows finding a combination of local amplification that increasing significantly the strength of structure. Namely, radius of the transition from the column to the support surface and in the openings between the column and the inclined belt up to 40 and $50 \mathrm{~mm}$ are increased respectively; truss plate are added between the upper and lower shelf of Triangel guide and on the inner guide of jaw aperture; technological area of the aperture in the column is reduced by one-third. Due to the proposed stresses combination, voltages in construction were reduced by $41 \%$. Originality. The efficiency of the iterative search procedure of local amplifications combinations in design of the side frame that let significantly increase its strength without a significant increase in weight is presented by scientists. Practical value. Obtained results give the possibility to increase significantly the strength of the side frame in the three-piece truck without any noticeable change in its geometrical and mass characteristics.

Keywords: side frame; three-piece truck; strength; modernization; strengthening

\section{REFERENCES}

1. Boronenko Yu.P., Orlova A.M. Obobshcheniye nakoplennogo opyta proyektirovaniya telezhek gruzovykh vagonov dlya sozdaniya ikh tiporazmernogo ryada [Best practice in bogies design of freight cars to create their standard series]. Visnyk Dnipropetrovskoho natsionalnoho universytetu zaliznychnoho transportu imeni akademika V. Lazariana [Bulletin of Dnipropetrovsk National University of Railway Transport named after Academician V. Lazaryan], 2004, issue 5, pp. 25-29.

2. Bubnov V.M., Mankevich N.B., Myamlin S.V. Sovershenstvovaniye konstruktsii bokovoy ramy dvukhosnoy telezhki gruzovykh vagonov [Improving the design of the solebar of the four-wheel truck in the freight car]. Vagonnyy park - Car Park, 2011, no. 2, pp. 36-39.

3. Davydov A.N., Smolyaninov A.V. Vliyaniye prodolnykh gorizontalnykh zazorov v bokovykh oporakh nepreryvnogo kontakta na velichinu kriticheskoy skorosti gruzovogo vagona [Impact of longitudinal horizontal gaps in side bearers of continuous contact on the critical speed of freight cars]. Vestnik Uralskogo gosudarstvennogo universiteta putey soobshcheniya [Proc. of Ural State University of Railway Transport], 2013, no. 1 (17), pp. 43-49.

4. Blokhin Ye.P., Alpysbayev K.T., Granovskiy R.B. Dinamicheskiye kachestva gruzovykh vagonov, imeyushchikh telezhki s diagonalnymi svyazyami [The dynamic properties of freight cars, having bogies with diagonal braces]. Visnyk Skhidnoukrainskoho natsionalnoho universytetu im. V. Dalia [Proc. of East Ukrainian Volodymyr Dahl National University], 2012, issue 5, part 1, pp. 12-16. 
5. Miamlin S.V., Matsiuk S. Prohnozuvannia rozvytku konstruktsii dvovisnoho vizka vantazhnoho vahona [The prediction of the two-axles development of freight car truck]. Visnyk Dnipropetrovskoho natsionalnoho universytetu zaliznychnoho transportu imeni akademika V. Lazariana [Bulletin of Dnipropetrovsk National University of Railway Transport named after Academician V. Lazaryan], 2009, issue 27, pp. 24-29.

6. Normy dlya rascheta i proyektirovaniya vagonov zheleznykh dorog MPS kolei $1520 \mathrm{~mm}$ (nesamokhodnykh) [The rules for the calculation and design of railway cars MRW, track $1520 \mathrm{~mm}$ (unpowered)]. Moscow, GosNIIV-VNIIZhT Publ., 1996. 352 p.

7. Golubenko A.L., Gubacheva L.A., Andreyev A.A., Mokrousov S.D. Osobennosti ramy telezhki gruzovogo vagona i ustalostnaya vynoslivost [Features of a bogie frame in the freight car and fatigue endurance]. Visnyk Skhidnoukrainskoho natsionalnoho universytetu im. V. Dalia [Proc. of East Ukrainian Volodymyr Dahl National University], 2013, issue 9 (1), pp. 7-16.

8. OST 32.183-2001 Telezhki dvukhosnyye gruzovykh vagonov kolei $1520 \mathrm{~mm}$. Detali lityye. Rama bokovaya $i$ balka nadressornaya. Tekhnicheskiye usloviya [BS 32.183-2001. Four-wheel truck in the freight car, track of $1520 \mathrm{~mm}$. Molded pieces. Solebar and the truck bolster. Technical conditions]. Moscow, MRW, Russia Publ., 2001. 22 p.

9. Bosov A.A., Myamlin S.V., Panasenko V.Ya., Klimenko I.V. Puti sovershenstvovaniya konstruktsii telezhki gruzovogo vagona [The ways of the freight train trucks design improvement]. Visnyk Dnipropetrovskoho natsionalnoho universytetu zaliznychnoho transportu imeni akademika V. Lazariana [Bulletin of Dnipropetrovsk National University of Railway Transport named after Academician V. Lazaryan], 2009, issue 29, pp. 27-32.

10. Kharybin I.A., Orlova A.M., Dodonov A.V. Sovershenstvovat khodovuyu chast gruzovykh vagonov [To improve the running gear of freight cars]. Vagony $i$ vagonnoye khozyaystvo - Car and Cars Facilities, 2009, no. 2 (18), pp. 26-29.

11. Bendsøe M.P., Sigmund O. Topology optimization. Theory, methods and applications. Berlin, Springer, 2004. 370 p. doi: 10.1007/978-3-662-05086-6.

12. Bubnov V., Myamlin S., Mankevych N. Theoretical And Experimental Investigations Of Strength Properties Of Cast Parts For Freight Cars Bogie With Axle Load Of $245 \mathrm{kN}$. Thesis of the $8^{\text {th }}$ Intern. Conference «TRANSBALTICA 2013 (09.05-10.05.2013)». Vilnius, 2013, pp. 9-13. doi: 10.3846/transbaltica2013.003 .

13. Claus H., Schiehlen W. Modeling and simulation of railway bogie structural vibrations. Vehicle System Dynamics, 1998, vol. 29, supp. 1, pp. 538-552. doi: 10.1080/00423119808969585.

14. Dietz S., Netter H., Sachau D. Fatigue life prediction of railway bogie under dynamic loads through simulation. Vehicle System Dynamics, 1998, vol. 29, issue 6, pp. 385-402. doi: 10.1080/00423119808969381.

15. Park B., Kim N., Kim Ju., Lee K. Optimum design of titling bogie frame in consideration of fatigue strength and weight. Vehicle System Dynamics, 2006, vol. 44, issue 12, pp. 887-901. doi: 10.1080/00423110600737106.

16. Park B.U., Lee K.Y. Bogie frame design in consideration of fatigue strength and weight reduction. Proc. of the Institution of Mechanical Engineers. Part F. Journal of Rail and Rapid Transit, 2006, vol. 220, issue 3, pp. 201206. doi: 10.1243/09544097f01405.

Статья рекомендована к публикации д.т.н, проф. И. Э. Мартыновым (Украина); д.т.н, проф. С. В. Мямлиньм (Украина)

Поступила в редколлегию 11.06.2015

Принята к печати 17.08.2015 